\author{
C. Welz, B. Srinivasan, D. Bonvin \\ Laboratoire d'Automatique \\ Ecole Polytechnique Fédérale de Lausanne \\ $\mathrm{CH}-1015$ Lausanne, Schweiz \\ O. Naef \\ Département de Chimie \\ Ecole d'Ingénieurs de Fribourg \\ $\mathrm{CH}-1705$ Fribourg, Schweiz
}

\title{
Optimierung einer Batch-Destillationskolonne unter Unsicherheiten basierend auf Messungen
}

Das Ziel der dynamischen Optimierung von binären Batch-Destillationskolonnen ist die Maximierung der Destillatmenge am Ende einer Charge bei gleichzeitiger Erfüllung der Endpunktbedingung für die Reinheit des Destillats. Das optimale Steuerungsprofil für das interne Rücklaufverhältnis $(0 \leq r \leq 1)$ wird durch 2 Intervalle angenähert:

1) Anlaufphase mit vollem Rücklauf $(r=1)$,

2) Destillationsphase zur Produktion des Destillats $(0 \leq r \leq 1)$.

Im Fall von Prozessunsicherheiten muss eine konservative und suboptimale Prozessführungsstrategie gewählt werden, um die Endpunktbedingung zu erfüllen.

Anstelle einer konservativen Strategie schlägt dieser Beitrag die Implementierung der notwendigen Optimalitätsbedingungen vor, die aus Rand- und SensibilitätsBedingungen bestehen. Entscheidend für das gegebene Optimierungsproblem ist es, die Randbedingungen zu erfüllen, insbesondere die Endpunktbedingung. Die Endpunktbedingung für die Reinheit des Destillats wird unter Verwendung von Messungen aktiv gehalten.

Dies kann während einer Charge durch die Verfolgung eines Referenzprofils für die Reinheit des Destillats realisiert werden. Anstatt ein Modell zu aktualisieren, welches die Endpunktbedingung während der Destillation voraussagt, wird das System durch Verfolgung des Referenzprofils zu der Endpunktbedingung geführt. Dieses Referenzprofil wird mit Hilfe eines Tendenzmodells des Systems bestimmt. Unsicherheiten in der Verdampfungsrate werden durch eine Vorregelung in Abhängigkeit von der Destillatmenge kompensiert, welche den Fortschritt der Destillation charakterisiert.

Die Methode ist in der Lage, die Konservativität zu reduzieren und die Produktivität unmittelbar zu steigern. Abbildung 1 zeigt die Verfolgung eines linearen Referenzprofils für die Reinheit des Destillats in einer Kolonne im Labormaßstab. Gegenüber einer suboptimalen Fahrweise mit konstanter Destillatzusammensetzung kann der Ertrag dabei um 11\% gesteigert werden. 


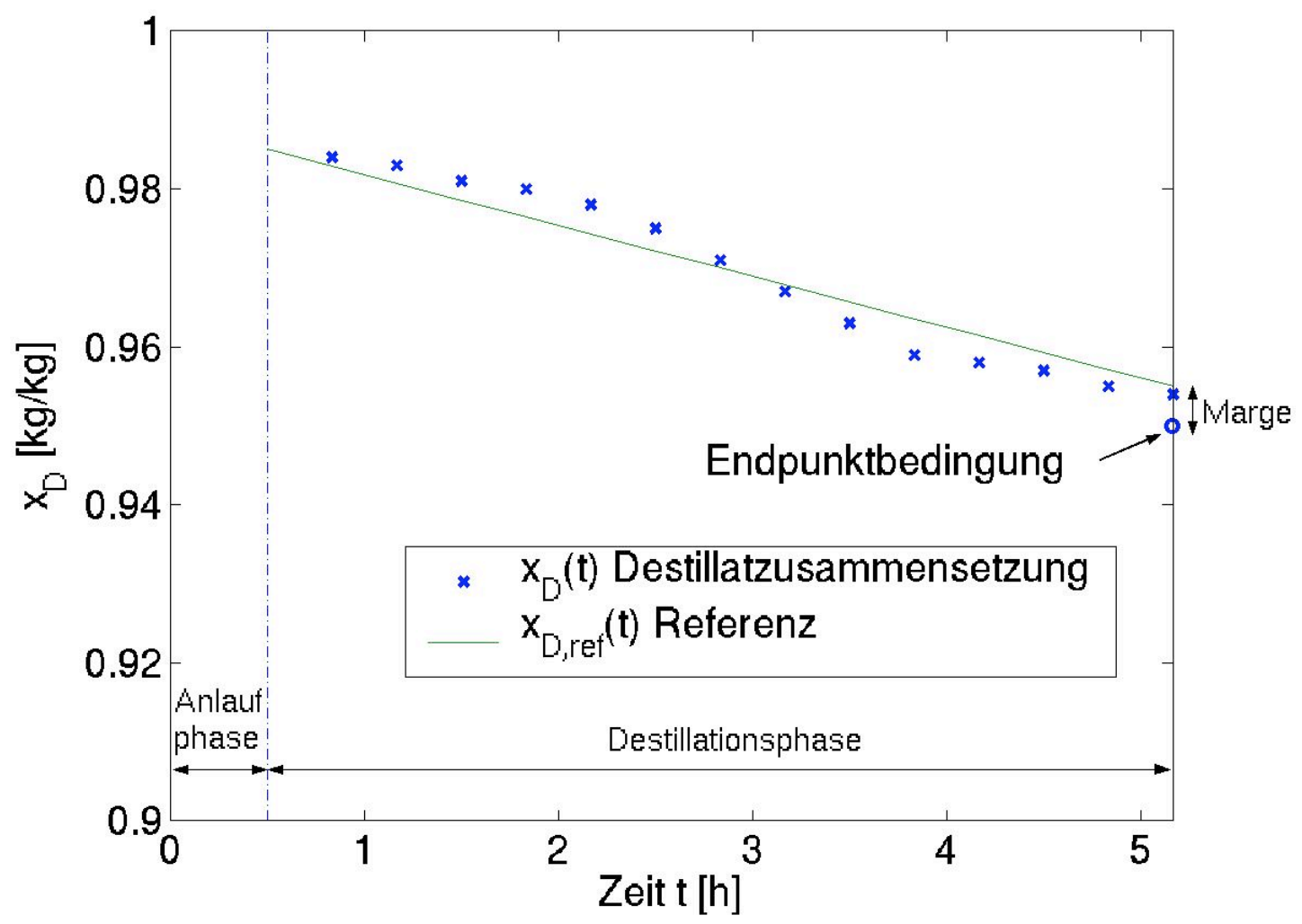

Abbildung 1: Verfolgung einer Referenz für die Destillatzusammensetzung mit dem Ziel, die Endpunktbedingung zu erfüllen. 